\title{
Methodology for process improvement through basic components and focusing on the resistance to change
}

\author{
Jose A. Calvo-Manzano ${ }^{1, * \dagger}{ }^{*}$, Gonzalo Cuevas ${ }^{1}$, Gerzón Gómez ${ }^{2}$, Jezreel Mejia ${ }^{1}$, \\ Mirna Muñoz ${ }^{1}$ and Tomás San Feliu ${ }^{1}$ \\ ${ }^{1}$ Universidad Politécnica de Madrid, Facultad de Informatica, Campus de Montegancedo s/n, 28660 Boadilla \\ del Monte, Madrid, Spain \\ ${ }^{2}$ Universidad Autonoma de Tamaulipas, Unidad Revnosa Rodhe, Mexico
}

\begin{abstract}
SUMMARY
This paper describes a multi-model methodology that implements a smooth and continuous process improvement, depending on the organization's business goals and allowing users to establish their improvement implementation pace. The methodology focuses on basic process components known as best practices $^{\prime}$. Besides, it covers following the topics: knowledge management and change management. The methodology description and the results of a case study on project management process are included. Copyright 92010 John Wiley \& Sons, Ltd.
\end{abstract}

KEY WORDS: project management; best practices; knowledge management; change management; process improvement: multi-model environment

\section{INTRODUCTION}

For many organizations, the lack of good project management is the main cause of project's failure: the projects can rarely be completed in time and within an acceptable cost $[1,2]$.

Regarding this, authors such as Pressman [3]. Walter [4] and Yager [5] argue that after 30 years of having identified "the software crisis", the problems related to project failures still continue. Moreover. Williams [6] mentions that nowadays the organization's management has become more project-based. As a result, the need to manage projects successfully in organizations is constantly increasing. However, if most organizations continue building software products in the same way as they did for years without analyzing whether their management processes are adequate or obsolete, how is this need satisfying? [7].

Even there is a growing group of process improvement success stories $[8,9]$; introducing process improvement for most organizations becomes 'a path full of obstacles and always away from the original path $[10,11]$. This is due to the fact that process improvement initiatives are not successfully implemented [12] or have limited success [13]. The main problem is the difficulty that an organization faces when tailoring the selected process improvement model to their current scenario [10].

The goal of this paper is to present an organizational process improvement methodology overview. This methodology will enable a smooth and continuous improvement depending on

\footnotetext{
${ }^{\ddagger}$ Cortespondence to: Jose A. Calvo-Manzano, Universidad Politécnica de Madrid. Facultad de Informática. Campus de Montegancedo s/n, 28660 Boadilla del Monte. Madrid. Spain.

E-mail: joseantonio.calvomanzano@upm.es
} 
their business goals, but allowing users to establish their improvement implementation pace. This will prevent initial resistance to change in the organization and the subsequent problems. Besides, the methodology is focused on basic process components known as 'best practices'. Fragidis and Tabanis [14] mention that best practices are a critical factor to increase an organization's process capacity and to achieve a competitive advantage. Therefore, this research work tries to answer the following questions:

- Why do actual software process improvement models and standards not have the expected performance when they are implemented in organizations?

- Why do improvement initiatives not have the expected results?

- Will the identification of organization's best practices allow a process improvement initiative to be successfully implemented?

This paper is structured as follows: Section 2 shows the research work context; Section 3 describes the proposed methodology: MIGME-RRC, methodology for a gradual process improvement to reduce change resistance; Section 4 shows a case study; and finally Section 5 shows the conclusions.

\section{RESEARCH WORK CONTEXT}

The proposed methodology covers process improvement, best practices, knowledge management, change management and multi-model environment. Each of the topics covered is described briefly.

\subsection{Process improvement}

Software Process Improvement (SPI) is a field of research and practice, arising out of the need to solve software development issues, increasingly complex and ubiquitous [15]. SPI is the action taken by organizations to change processes, taking into account the business needs and achieving their business goals more effectively [16].

SPI has become the primary approach for improving software quality and reliability, employee and customer satisfaction and return on investment [17]. Different paradigms such as Quality Improvement Paradigm (QIP) [18] and methods and models for assessing the current capacity and/or maturity levels of organizations (such as SCAMPI [19] and ISO/IEC 15504 [20]) or for implementing process improvement initiatives (such as ISO/IEC 15504 [20] or IDEAL [21]) have been developed. However, implementing the methods mentioned above remains a high risk in many organizations.

According to Pries-Heje et al. [22], investments in SPI often have not achieved the expected changes and improvements. This is because the protocol followed by current process improvement is: (1) analyze the company weaknesses, (2) design their processes, often based on international models and standards, beyond the activities carried out in the company, and (3) implement the processes developed in depth within the organization (too many changes at the same time that are too large or too fast) [23].

This way of implementing a process creates a process revolution, generating change resistance that leads to a failure in the process improvement initiative.

\subsection{Best practices}

Williams [6] refers to best practices as building blocks of organizational learning and organizational knowledge but, what is a best practice?

According to Whiters [24]. 'a best practice conld be a management or technical practice that has consistently demonstrated to improve one or more aspects such as productivity, cost, schedule, and quality or user satisfaction".

In this context, introducing best practices at the speed supported by the organization is a key element for improving the quality and the productivity $[25,26]$. 
Owing to the importance of best practices, relevant institutions such as the Software Engineering Institute (SEI), the Project Management Institute (PMI), the Institute of Electrical and Electronics Engineers (IEEE) and the International Organization for Standardization (ISO) have been focused on the study of best practices. They have developed best practices reference models and standards [27].

The most widespread models and standards developed by these institutions are as follows: CMMI-DEV v1.2, TSP, PMBOK, COBIT, PRINCE2, ISO/IEC15504, ISO 9001: 2000 and ISO/IEC12207 [28].

However, although a wide variety of models and standards have been developed. West [23] highlights that the current problem in organizations is the identification of best practices. This problem is becoming one of the main challenges facing the new process generation.

Identify successfully the best practices of an organization allows to have a baseline related to its strengths when developing an improvement initiative.

\subsection{Knowledge management}

According to Burke and Howard [16], Knowledge Management (KM) is a systematic approach to facilitate the flow of data, information and knowledge to the right people at the right time, so they can act more efficiently and effectively. In this way, its importance for generating value and building a competitive edge in organizations is well recognized.

Besides, according to Williams [6], KM allows the capture, codification, use and exploitation of the knowledge and experiences to develop better tools and methods, as well as to develop a willingness and ability to use these methods.

Therefore, KM requires an organizational effort to build, operate, maintain and spread a knowledge-sharing environment. The organization by itself should be able to: (1) retrieve and understand the structured and unstructured data, (2) convert data into useful information and (3) share the knowledge [16].

\subsection{Change management}

All improvements imply changes; unfortunately most change initiatives fail because the inability to support the changes is widely repeated despite the substantial resources dedicated to the improvement effort, the people with necessary skills involved and everything supporting it [2].

Besides, it is necessary to take into account that changes' scope, their competition with others or their speed can overwhelm the organization, destroying its investment in organizational process assets and generating a degree of organizational stress that becomes a banier to change [28].

Therefore, change management is the process of planning, organizing, coordinating and controlling internal and external components in order to ensure that process changes are implemented with the minimum deviation compared to approved plans and overall changes' introduction goals.

\subsection{Multi-model environment}

People experience fear and dread due to common failures related to model-based process improvements [29]. As a result, organizations throughout the world, in their effort to achieve a successful software process improvement, are turning to an integration of international standards and models $[30,31]$.

However, the difficulty in implementing process improvement successfully in multi-model improvement environments is well known. A first step in integration is to recognize that despite the different structures and terminologies, and despite different levels of abstractions, the standards and models used in the organization share common element types. The challenge is to examine the models to identify these common elements and then use and tailor them according to the organization needs $[28,32]$.

According to [33], the goals of a multi-model are as follows: reduce redundancy, improve integration, create synergy, leverage best practices and make transparent frameworks. Therefore, a 
multi-model process is characterized by a harmonized and unified approach to process improvement through implementation of multiple models [31].

A multi-model process may contain three common elements: best practices elements, improved methods and institutionalization elements [31, 34].

\section{MIGME-RRC METHODOLOGY}

The purpose of this research work is to develop a methodology whose goal is to incorporate elemental process improvement components. The methodology will enable a smooth and continuous improvement depending on the organization's business goals but allowing users to establish their improvement implementation pace. This will prevent initial resistance to change in the organization and the subsequent problems.

This methodology uses a bottom-up approach to software process improvement, which consists of identifying the internal best practices and promoting their use.

The best practices reinforce the organization's learning by documenting practices that have good results and promoting their use so that the key organizational knowledge is preserved and transmitted. Then, the external best practices proposed by most widespread models and standards through a multi-model environment, which complement the current practices and fit to the culture of the organization, could be included.

Figure 1 shows the methodology scheme called MIGME-RRC: methodology for a gradual process improvement to reduce change resistance.

\section{CASE STUDY}

\subsection{Methodology development and implementation environment}

Everis is a multinational consulting firm with factories in Europe and Latin America where they develop and implement best practices to improve the performance of its factories. It offers services that provide solutions to large companies in any sector and it is based on three pillars: innovation, methodologies and efficiency through the use of specialists. The specialists use specific knowledge for each project in order to optimize time, cost and productivity.

Since its creation in 1996, it has grown both in invoicing and staff in a constant and always organic way. Its 2008 turnover was over $300 \mathrm{M} €$ and more than 6000 employees, and the number of projects that remain open every month is greater than 1000 .

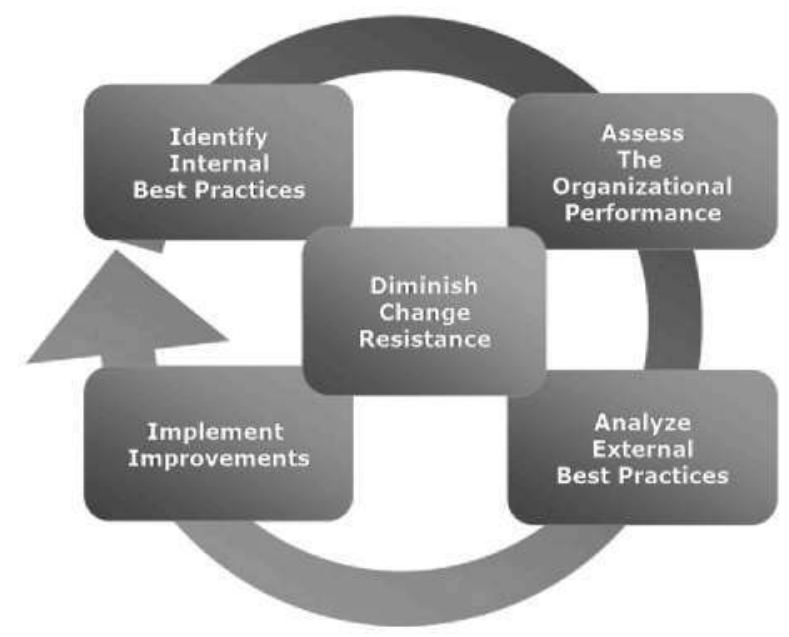

Figure 1. MIGME-RRC methodology. 
Table I. Indicators measured by Everis over the 2007-2008 period.

Indicators and Percentage

The percentage of management rules that are not right and not approved by the customer must be no more than $5 \%$

The percentage of project planning that is not current and feasible must be no more than $5 \%$

The percentage of start-up minutes that are not right and not approved by the customer must be no more than $5 \%$

Christie and Fisher in [35] mention that, to successfully implement a process improvement in this kind of organization, it must deal with a dynamical change conditions (in terms of growth, personal turnover and product evolution), in order to prevent a series of unpredictable changes with unforeseen consequences.

Besides, there is a risk of incorporating deep changes (too many changes at the same time being canied ont too fast) based on external process implementation. These changes are accepted by neither the organization nor the staff. Therefore, the change resistance is caused by the uncertainly and lost of control that they assume the changes will produce.

\subsection{Implementation on project management processes improvement}

The scope of the methodology implementation is focused on Everis project management. Project management has a broad impact on their business goals and is measured in accordance with a series of objectives. Table I shows the most representative indicators related to the objectives that have been measured over the 2007-2008 period.

It is considered important to give a brief description of the indicators in order to understand their importance: (1) the management rules are a key document in the methodology because they define a project development framework, its detail planning and its management procedures; (2) the project planning documentation must be accurate and up-to-date at all times in order to have a proper overview of the project and, if necessary, to take the right decisions and (3) the start-up minutes in order to come to an agreement with the client on the operational aspects of the projects.

It is important to highlight that the required level is very high; for example. if the plan is not updated or the management rules are not approved by the client, then the related indicator is not satisfied.

The implementation of the methodology focuses on project management carried out by account managers because: (1) they carry out the project management (heading one or more projects), and (2) they are in charge of projects. Besides, managers and project managers have a significant role in the best practices identification and validation feedback.

\subsubsection{Methodology phases. In the following sections the methodology phases are presented.}

4.2.1.1. Identify internal best practices. The purpose of this phase is to analyze what practices are already carried out in the organization. If the practices are identified, it will be possible to get an overview of the current process.

Figure 2 shows the analysis carried out in the organization, in order to identify the current practices. The followed steps are:

- Conduct interviews with the organization's managers.

- Analyze the information gathered from interviews, make activities diagrams for each interview and validate them with the interviewed accounting managers.

- Map the activities of all approved activities diagrams, in order to get a set of activities called 'generic activities'. Then, make a diagram with the generic activities.

- Analyze the formal process documentation.

- Map the generic activities diagram with those included in the formal process documentation. It allows identifying the current organization's activities. 


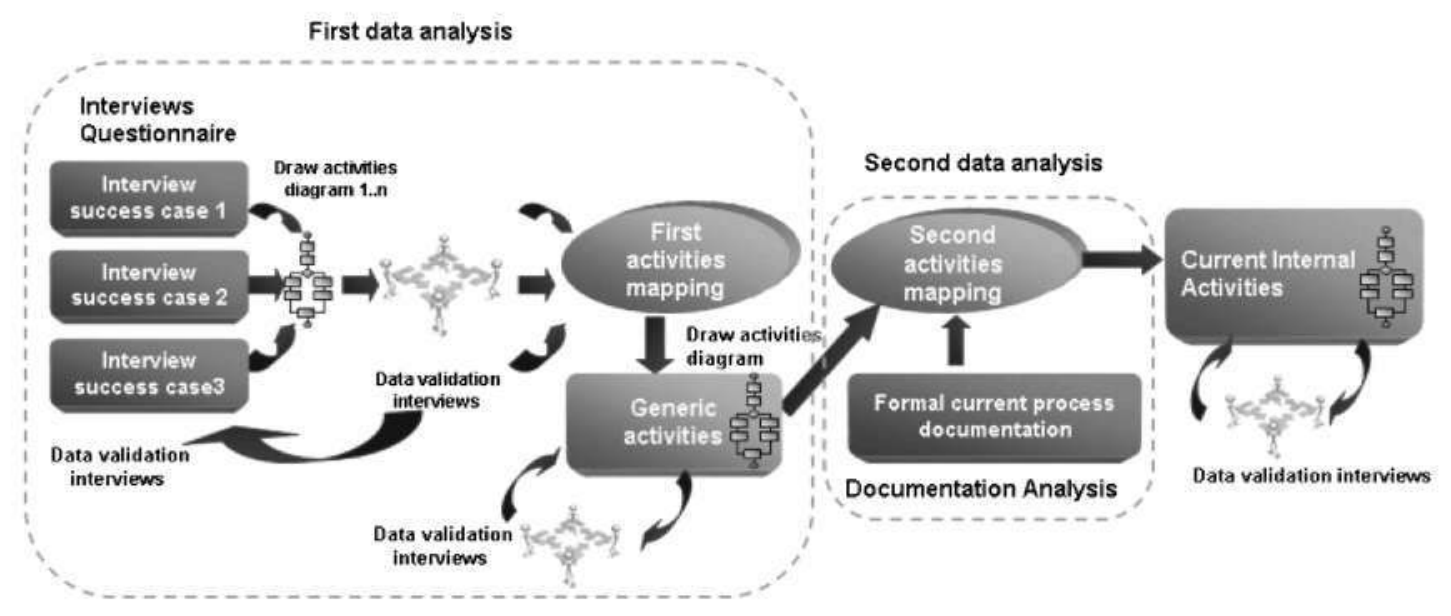

Figure 2. Best practices identification steps.

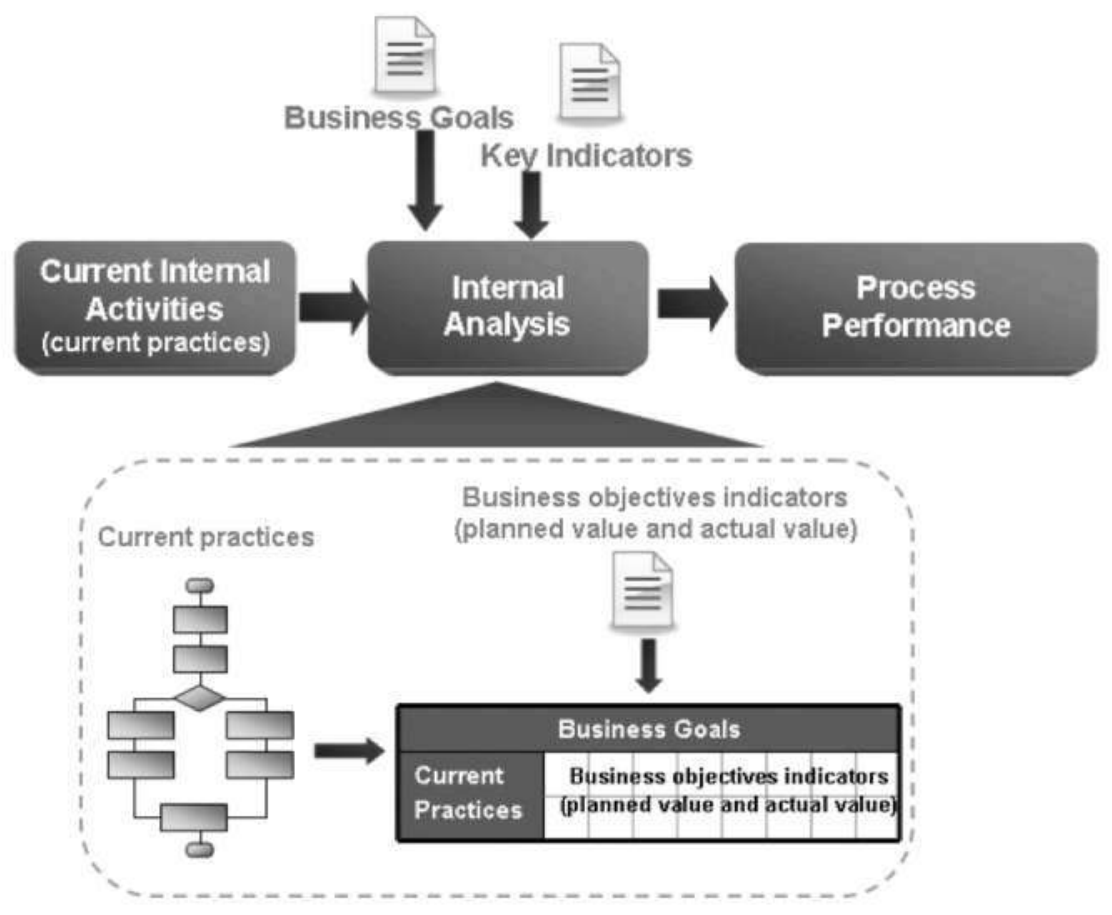

Figure 3. Organizational performance assessment.

4.2.1.2. Assess organizational performance. Once the current practices are identified, the organizational performance should be assessed in order to know the organization's performance related to the current practices. Figure 3 shows how the organizational performance was analyzed; the current activities, business goals and key indicators are used as input source. The followed steps are:

- Collect and analyze any formal documentation about planned values of indicators related to organizational business goals.

- Collect actual values of the indicators.

- Make a matrix of business goals indicators and generic activities.

- Analyze the achievement of business objectives according to the planned value and the matrix, and establish a performance overview.

- Prioritize the business goals to be achieved. 


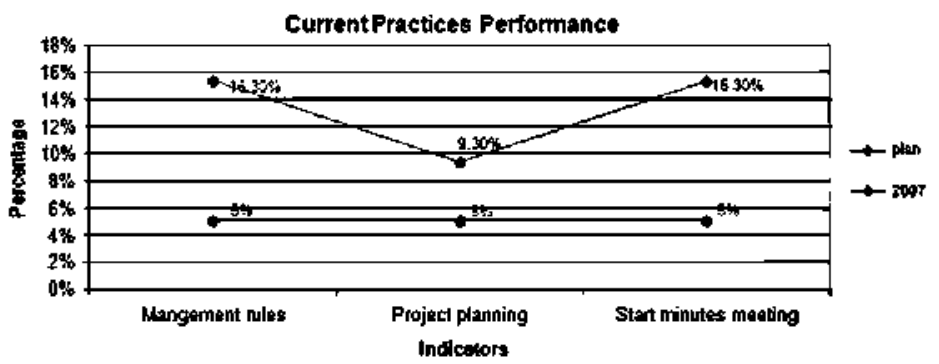

Figure 4. Everis audit results.

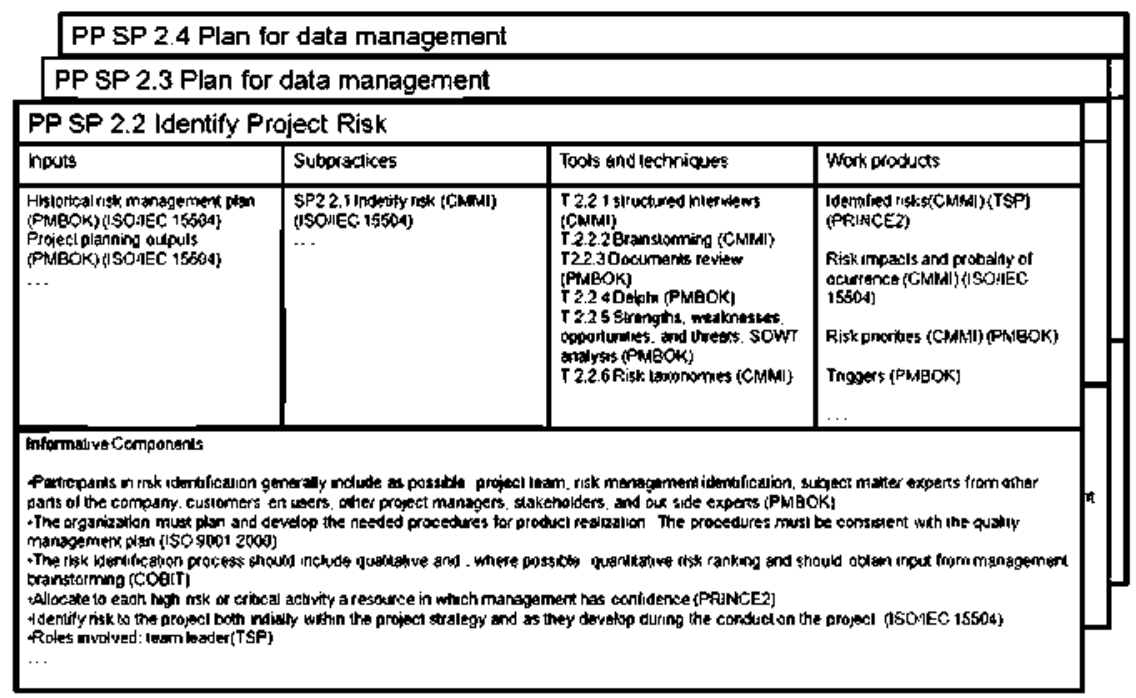

Figure 5. Tables of candidate practices to be included.

In the case of Everis, internal control andits were taken as input source. Figure 4 shows the percentage of business objectives Everis achieved with the current practices. The analysis of the indicators will allow the project management to make an internal project characterization.

The analysis of Everis audits allows establishing an overview of the achieved key indicators taking into account the current practices. Although the three percentages of the indicators analyzed are not too far from the planned percentage, all of them should be improved, because of its importance for achieving the business objectives.

4.2.1.3. Analyze external best practices. In this phase, the performance of similar models and standards were analyzed in order to establish a multi-model environment. The models and standards included in the study are as follows: CMMI-DEV v1.2, PMBOOK, PRINCE2, TSP, COBIT, ISO9001 and ISO/IEC 15504. The followed steps are [27]:

- Select the models and standards to be analyzed.

- Choose the reference model.

- Select the process.

- Establish the detail level.

- Create a correspondence template.

- Identify the similarity among models.

- Show the obtained results.

As Figure 5 shows, the tables, which are the results of the study, contain the candidate practices to be included. So that, the study indicates project management external best practices, where performance is proved, that could be executed by the organization. 
4.2.1.4. Implement improvements. The purpose of this phase is to integrate the internal best practices with the external best practices. On the one hand, the internal best practices contain all the organization's knowledge and experience. On the other hand, the external best practices through a multi-model environment have a proven efficiency in other organizations, and best fit with the way the organization works.

The way that best practices will be integrated and incorporated depends on their dependence and importance in achieving the business goal. The followed steps are:

- Identify the change resistance factors and risks associated with the improvement initiatives. Because in many cases, both are important factors that make difficult an improvement initiative implementation and lead it to the failure.

- Analyze the external best practices of the multi-model environment, taking into account practice dependences and its impact on achieving business goals according to the prioritization of business goals done in previous phase.

- Enable a set of best practices to be selected.

- Develop or refine the improvements that allow the users to select the practices in a smooth and continuous way. These best practices will always be selected in a pace established by users.

In the case of Everis, the improvements (containing the best practices identified and a set of external practices to be incorporated) were grouped in a project management method, owing to the need of the organization to develop a project management method to be integrated in its COrporate Methods methodology (COM).

Figure 6 shows the process improvement implementation through the project management method overview. The method gathers all the Everis knowledge, experiences and best practices. Besides, when enabling a set of best practices it will be possible to establish a marked-up user environment for improving processes continuously.

Once the method was developed, it was validated and approved by the quality and methodology Everis group. Then, pilot projects were performed. The purpose of the pilot projects was to

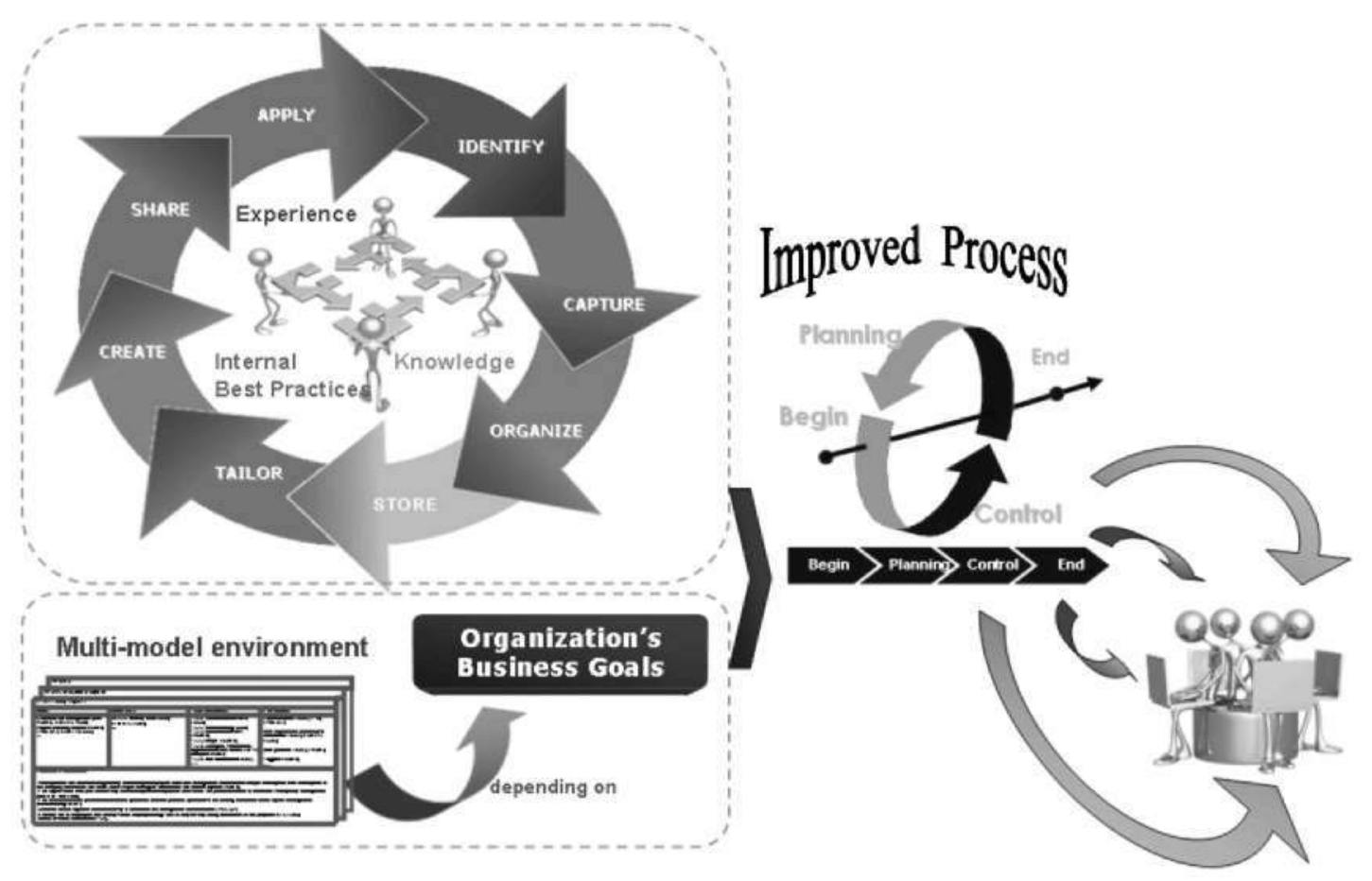

Figure 6. Process improvement implementation through COM project management method. 
launch a better version of the COM project management method. The launch allowed testing the method and after analyzing their results, deploying them as an experience of using best practices.

Using pilot studies reduces the risk of rolling out a flawed process, procedure or other solution component. Besides, experiences in pilot studies always expose improvement opportunities that can be exploited to tune and refine the improvement process before a broader dissemination $[26,36,37]$.

The chosen pilot projects features in order to reduce risk in implementing the method were as follows: (1) size medium (duration time not greater than 3 months); (2) budget: $100000-150000 €$; (3) staff: 4-7 people and (4) project manager profile: junior project leader.

Meetings with the project managers were held to gather information about the improvement. During the interviews, their comments on project management method acceptance and usefulness in the project management were gathered.

4.2.2. Improvement measurement and results. Three measures were defined in order to analyze the improvement: process use (M1), process performance (M2) and process acceptance (M3). The approach involves gathering information: before, during and after the change.

This approach allows getting better improvement performance information. According to Kasunic [26,36], typical approaches that fail are those whose measurable observations are done before the change or after the change.

Process use $(\mathrm{Ml})$ : its purpose is to analyze the degree of best practices performance. The measure data were obtained from the Madiid office internal audits. Figure 7 shows the results obtained by comparing the planned percentage against actual percentage in 2007 and 2008 . In 2008, an improvement was observed in the project planning practices and start-up minutes indicators; both were $5 \%$.

Process performance $(M 2)$ : its purpose is to analyze the process performance obtained with the improvement. The measure data were obtained from Madrid office delivery projects. Figure 8 shows the obtained results by analyzing those who have any type of internal cost deviation (either

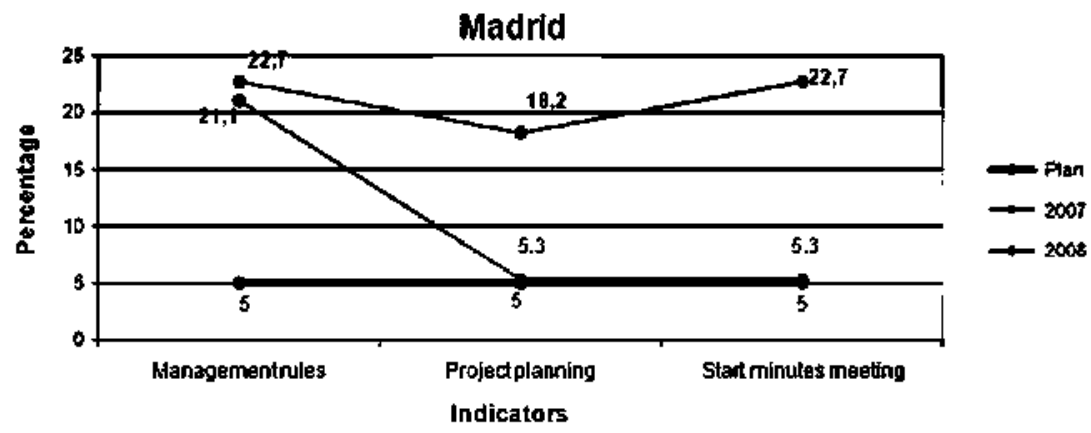

Figure 7. Madrid office best practices performance.

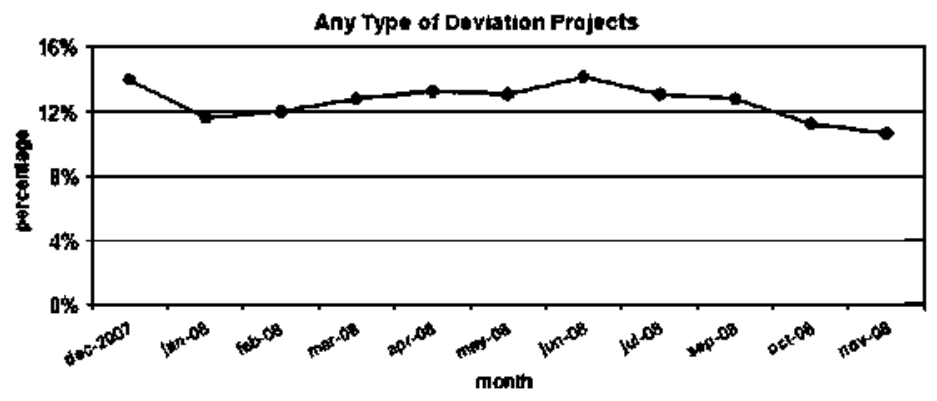

Figure 8. Projects with internal deviations. 

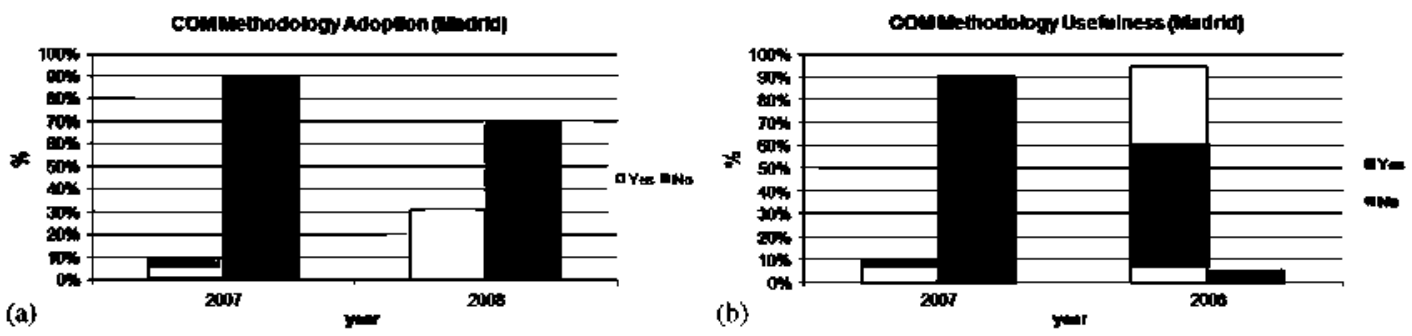

Figure 9. Improvement acceptation by users.

in incurred hours, external costs or subcontracting). However, the deviations did not affect the time limits agreed with customers.

An improvement in delivery projects which have any type of deviation was observed because the percentage of projects with deviations decreased from 13.99 to $10.63 \%$.

Process acceptation (M3): its aim is to analyze the process acceptation by users and, therefore, it allows checking the reduction in change resistance. The measure data were obtained by analyzing surveys carried out by Madrid office users involved in project planning.

Figure 9 shows two graphics with the improvement acceptance results obtained. In graphic 9 (a), an improvement in the adoption of the COM methodology is observed (from $10 \%$ in 2007 to $31 \%$ in 2008). In graphic 9(b), an improvement in the usefulness of the COM methodology is observed (from $10 \%$ in 2007 to $95 \%$ in 2008 ).

\section{CONCLUSIONS}

The implementation of external processes in the organization is the main cause of process improvement initiatives failure. This involves a high cost for assimilating the appropriate knowledge and deploying the process, and a big cultural change.

MIGME-RRC shows that beginning a process improvement initiative by identifying the organization's best practices and involving the relevant stakeholders (chosen by the organization's senior management as success stories) has allowed extracting. collecting and formalizing the tacit knowledge of the organization.

Having the knowledge in a formal way, it is possible to select a set of external best practices based on the way the organizations work, but in accordance with their business goals. It reduces the staff's resistance to change when implementing process improvement initiatives.

Besides, the reduced change resistance was achieved because of a smooth and continuous best practices implementation, and most of all, the changes are introduced by users and, therefore, approved by relevant stakeholders.

The methodology allows different units of a software intensive organization to set their improvement pace and choose those practices that best fit their work, thereby doing it more efficiently. At the same time, there is a uniform process capacity through the organization. Therefore, the communication of improvement results is a key point.

Finally, the implementation of MIGME-RRC for a smooth and continuous improvement performed in Everis confirms that staff only accepts assimilated changes with identified benefits. In this way, they perceive the change as an evolution of their work.

\section{ACKNOWLEDGEMENTS}

This work is sponsored by everis Foundation and Universidad Politécnica de Madrid through the Software Process Improvement Research Group for Spain and Latin American Region. Deserves special mention the support provided by Everis providing data and allowing the inplementation of the pilots, withont its help the implementation of this research work would not be possible. 


\section{REFERENCES}

1. Persse J. Project Managemem Success with CMMI. Prentice-Hall: Englewood Cliffs NJ. $2007 ; 321$.

2. Senge P. Kleiner A, Roberts Ch. Ross R. Roth G. Smith B. La Danza del Cambio: mas alla de la quinta disciplina, Gestion 2000. S.A.: Spain. 2000; 11-17. ISBN: 978-84-8088-421-1.

3. Pressman R. Ingenieria del Software Un Enfoque Practico (Sexta edición). MoGraw-Hill: New York, 2006; $640-662$

4. Walker R. Software Project Management A Unified Framework. Addison-Wesley: Reading MA. 1999; 5.

5. Yager S. Top 10 Project Management Problems. CEO Artemis International, 2001. Available at: http:/dssresources. com/papers/features/yager 10032001.htm [6 Febnary 2008].

6. Williams T. How do organizations learn lessons from projects-And do they? IEEE Transactions on Engineering Management 2008; 55(2):248-266. DOI: 10.1109/TEM.2007.912920.

7. Gainer J. Best Practices: Informal, Effective Process Impro'ement, Jeff Gainer's Critical Path. 1998. Available at: http://www.itmweb.com/f041598.htm [10 October 2007].

8. Software Engineering Institute (SEI). CMMI Performance Results. TATA Consultancy Services, Software Engineering Institute (SEI), Carnegie Mellon University, 2008. Available at: http:/www.sei.cmu.edu/cmmi/resultst org29.html\#BC2 [7 March 2007].

9. Gibson D. Goldenson D. Kost K. Performance results of CMMI-based process improvement. Technical Report $C M U / S E I-2006-T R-004$ ESC-TR-2OOK-OO4. Software Engineering Institute (SEI), Carnegie Mellon University, 2006.

10. Morgan P. Process improvement-Is it a lottery? Sofiware Development Magazine. UML, Agile, Programming, Software Testing, Quality Assurance and Project Management, 2007. Available at: http:/www.methodsandtools. com/archive/archive.php?id=52 [20 January 2009].

11. Potter N, Sakry M. Making Process Improvement Work: A Concise Action Guide for Software Managers and Practitioners. Addison-Wesley: Reading MA. 2006; $2-5$.

12. Goldenson D. Teach views, performance outcomes from process improvement. Sofiware Technology News 2007: 10(1).

13. Conradi H, Fuggetta A. Inproving software process improvement. Software IEEE 2002; 19(4):92-99. DOI: $10.1109 / \mathrm{MS} .2002 .1020295$.

14. Fragidis G. Tarabanis K. From repositories of best practices to networks of best practices. IEEE Intemational Conference on Management of Imovation and Technology 2006; 19(4):92-99. DOI: 10.1109/ICMIT.2006.262186.

15. Kautz K, Levine L, Hefley B. Johansen J, Kristensen C, Nielsen P. Networked Technologies-The Role of Networks in the Diffusion and Adoption of Software Process Improvement (SPI) Approaches. Software Engineering Institute (SEI), Carnegie Mellon University, 2004.

16. Burke G. Howard W. Knowledge management and process improvement: A union of two disciplines. CrossTalk: The Journal of Defense Software Engineering. 2005. Available at: http:/www.stsc.hill.af.mil/crosstalk/2005/ 06/0506Burke.html [7 March 2007].

17. Mathiassen L. Ngwenyama OK, Aaen I. Managing change in software process improvement. IEEE Software 2005: 22(6). DOI: $10.1109 / \mathrm{MS} .2005 .159$.

18. Basili V, Caldiera G. Rombach HD. The experience factory. 2002. Available at: https://wwwagse.informatik. unikl.de/pubs/repository/basili94c/encyclo.ef.pdf [28 October 2007].

19. Members of the Assessment Method Integrated Team. Standard CMMI ${ }^{\circledR}$ Appraisal Method for Process Improvement (SCAMPI), Version 1.1, Handbook CMU/SEI-2001-HB-001. Software Engineering Institute (SEI). Carnegie Mellon University, 2001.

20. International Organization for Standardization. ISO/IEC 15504: 2004 Information Technology-Process Assessment Model (1st edn). International Organization for Standardization: Switzerland. 2004.

21. McFeeley B. IDEALSM: A user's guide for software process improvement. Handbook CMU/SEI-96-HB-001. Software Engineering Institute (SEI), Carnegie Mellon University. 1996.

22. Pries-Heje J, Christiansen M, Johansen J, Korsa M. The ImprovAbility ${ }^{\mathrm{TM}}$ Model. CrossTalk: The Joumal of Defense Software Engineering, 2007. Available at: http:/www.stsc.hill.af.mil/crosstalk/2007/02/ 0702 hejejohansenchristiansenkorsaa.html [10 May 2008].

23. West D. Enough process let's do practices: An introduction to EssWork and EssUP. Information Technology (IT) Conference 2007, 2007.

24. Withers D. Software engineering best practices applied to the modeling process. Proceedings of the 2000 Winter Simulation Conference, 2000.

25. Beynon D. Interpreting capability maturity model integration (CMMI) for business development organizations in the government and industrial business sectors. Technical Note, Software Engineering Institute (SEI), Carnegie Mellon University. 2007.

26. U.S. Department of Defense, OSD Comptroller iCenter. Best Practices \& Benchmarking: Making Worthwhile Comparisons, 2004.

27. Kasunic M. An Integrated View of Process and Measurement, Software Engineering Institute (SEI). Carnegie Mellon University, 2003.

28. Calvo-Manzano JA, Cuevas G, Muñoz M, San Feliu T. Process similarity study: Case study on project planning practices based on CMMI-DEV v1.2. EuroSPI 2008 Industrial Proceedings, 2008. ISBN: 978-87-7398-150-4. 
29. Mogilensky J. Pathological box-checking: The dark side of process improvement. SEPG 2009 Conference, 2009.

30. OST SEPG, CMMI, ISO, and ANSI 748. High value and easier than you think. SEPG Conference 2009, 2009.

31. Srivastava N, Singh S, Dokken T. Assorted chocolates \& cookies in a multi-model Box. SEPG Conference, 2009.

32. Kirwan P, Andelfinger U, Sassenburg H, Heijstek A. A Unified Process Improvement Approach for Multi-model Improvement Environments. Software Engineering Institute (SEI), Carnegie Mellow University, 2004. Available at: http://www.sei.cmu.edu/news-at-sei/features/2006/04/feature-1-2006-04.htm [13 November 2007].

33. Lawrence J, Becker N. Implementing insights and lesson learned using ISF for excellence. SEPG 2009 Conference, 2009.

34. Siviy J, LynnPenn M, Robert S. Achieving Success Via Multi-model Process Improvement. Software Engineering Institute (SEI), Carnegie Mellow University. Available at: http://www.sei.cmu.edu/sema/presentations/multimodel.pdf [13 November 2007].

35. Christie A, Fisher D. Simulating the emergent behaviour of complex software-intensive organizations. ProSim 2000 Workshop, 2000.

36. Kasunic M. Conducting effective pilot studies. SEPG 2004 Conference, 2004.

37. Fowler P, Rifkin S. Software engineering process group guide. Technical Report CMU/SEI-90-TR-O24 ESD-90TR-225, Software Engineering Institute (SEI), Carnegie Mellon University, 1990.

\section{AUTHORS' BIOGRAPHIES}

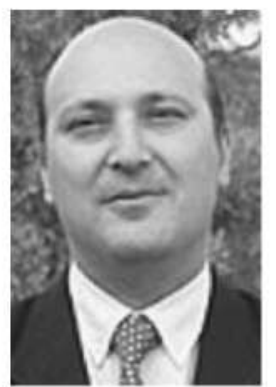

Jose A. Calvo-Manzano is a $\mathrm{PhD}$ in Computer Science. He is assistant professor in the Faculty of Computer Science at the Technical University of Madrid. He teaches in the area of Software Engineering, specifically in the domain of software process management and improvement. He has participated in more than 20 research projects (European and Spanish Public Administration). He is the author of more than 50 international papers and of books related to software process improvement and software engineering topics. He is a member of the SOMEPRO research group, where his main research field is process improvement, focusing on SMES, mainly in the topics of requirements management, project management, process deployment, and solicitation and supplier agreement development. He is a member of the team that translated CMMI-Dev1.2 into Spanish.

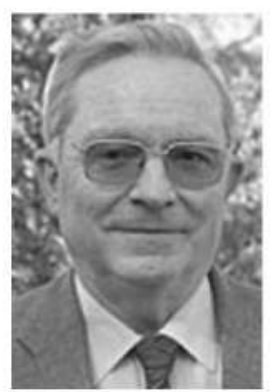

Gonzalo Cuevas received an Engineering degree in Telecommunications in 1965 and a $\mathrm{PhD}$ in Telecommunications in 1974. He also received an MS in Computer Science from the Technical University of Madrid in 1972. He has been vice dean of the Faculty of Computer Science at the Technical University of Madrid, where he is a full professor since 1970. He worked for Iberia Airlines as Software Development Director, supervising over 200 technicians, Data Processing Centre Director, Data Transmission Software Development Director, and the person in charge of strategic planning and software process improvement. He led European projects on software best practices from 1991 to 1995. His main research field is software engineering, including both technology (methods, techniques, and formalisms) and management. His current research interest is process models and methods, and transition packages. He is a member of ACM, senior member of IEEE, member of the Telecommunication Engineering Association and a member of the Computer Sciences Association. He is a member of the team that translated CMMI-Dev1.2 into Spanish.

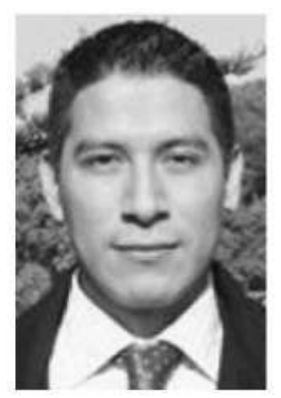

Gerzon Gómez is a BSc in Computer Science from the Autonomous University of Tamaulipas (UAT), Mexico. He was assistant professor in the same university. He has occupied many management positions during his more than 4 years in the industry. He has published several technical papers on IT Service Management. Currently, he is a $\mathrm{PhD}$ student in the Faculty of Computer Science of the Polytechnic University of Madrid, Spain. He works in a 'Metamodel for Service Level Management'. He is a member of the team that translated CMMI-Dev1.2 into Spanish. 


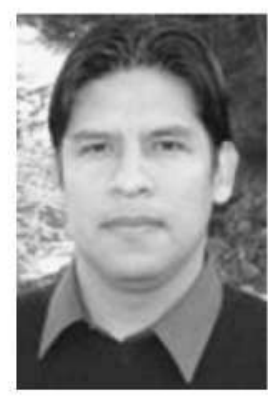

Jezreel Mejia is a Master in Computer Science (2003-2005) and Computer Science Engineer (1996-2000) from the Institute Technological of Orizaba University of México. $\mathrm{He}$ is a Software Engineering $\mathrm{PhD}$ student from the Faculty of Computer Science at the Technical University of Madrid. His research field is Software Engineering. His current research interest consists of outsourcing process improvement. He has published several technical papers on acquisition process improvement. He is colaboring with an Everis Foundation research project. He is a member of the team that translated CMMI-Dev1.2 into Spanish.

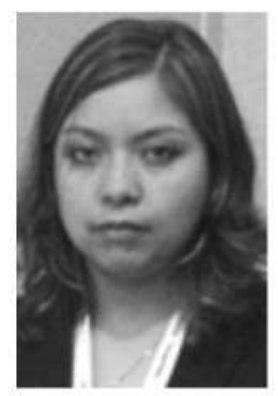

Mirna Muñoz is a Master in Computer Science (2002-2004) and is a Computer Science Engineer (1996-2000) from the Technological Institute of Orizaba University of México. She is a Software Engineering $\mathrm{PhD}$ student from the Faculty of Computer Science at the Technical University of Madrid. Her research field is Software Engineering. Her current research interest consists of the development of a methodology whose goal is to incorporate process improvement focusing on diminishing change resistance. She has published several technical papers on project management and process improvement. She is colaboring with an Everis consultants research project. She is a member of the team that translated CMMI-Dev1.2 into Spanish.

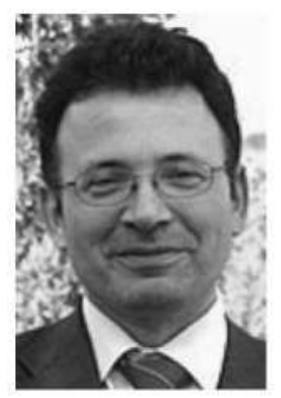

Tomás San Feliu is a $\mathrm{PhD}$ in Computer Science. He has been working for 15 years in the Software Engineering field as a programmer, associate and assistant professor and consultant. He has been involved in CMM appraisals in Spain and Latin America. As a Software Engineering assistant professor at the Technical University of Madrid, his main research field is in software process and software process improvement. His current research interest includes project management and risk management. He has published several books on process improvement and he has published technical papers in software engineering and software process improvement. He is a member of the team that translated CMMI-Dev1.2 into Spanish. 